\title{
PROMPT ANNOUNCEMENT AND CORRECTION OF A SERIOUS MISTAKE IN THE BINDING OF THE MARCH ISSUE OF THIS JOURNAL
}

\author{
WILLIAM J. GIES
}

By accident, pages 53 and 54 of this volume, in the paper by McClendon in the March issue, were omitted from that number when the copies were bound.

These two missing pages immediately follow this announcement They are appended to this issue, in place of the usual section on "proceedings of dental and stomatological societies," in order to isolate these pages conspicuously. We hope in this direct and special way not only effectively to announce and correct the oversight, but also to facilitate proper disposition of these two pages in the permanent binding of this volume.

We apologize for the error, and deeply regret the annoyance it has given, and will continue to give, to the readers of this JouRNAL.

Because of the omission from this issue of the section on "proceedings of dental and stomatological societies," that section in our issue for September will be correspondingly larger than usual. 